\title{
Intrathecal pain management: a team-based approach
}

\author{
This article was published in the following Dove Press journal: \\ Journal of Pain Research \\ 3 November 2017 \\ Number of times this article has been viewed
}

\author{
Jeremy A Adler' \\ Neona M Lotz ${ }^{2}$ \\ 'Pacific Pain Medicine Consultants, \\ Encinitas, ${ }^{2}$ Cypress Ambulatory \\ Surgery Center, Santa Maria, CA, USA
}

Objective: Physician assistants (PAs), nurse practitioners (NPs), and registered nurses (RNs) provide professional services on pain management teams. This review provides an overview of the practical management of chronic pain with intrathecal (IT) therapy using an interprofessional approach (eg, physicians and other health care professionals), with a focus on the contributions of PAs, NPs, and RNs.

Methods: Narrative review based on literature searches of the Medline database and treatment guidelines on the use of IT therapy in the management of patients with chronic pain.

Results: The specific roles and responsibilities of PAs, NPs, and RNs in the management of patients receiving IT therapy vary by practice. In many pain treatment centers, PAs, NPs, and RNs are responsible for patient education, postimplant maintenance, and ongoing supportive care of patients receiving IT therapy. Topics that we address include patient selection, patient expectations and goal setting, medication selection, outcome assessment, and treatment adjustment. Currently, morphine and ziconotide (a nonopioid, selective N-type calcium channel blocker) are the only agents approved by the US Food and Drug Administration for IT analgesia. We provide relevant information on the dosing, titration, and adverse effect management of these medications for PAs, NPs, and RNs responsible for administering IT therapy.

Conclusion: PAs, NPs, and RNs are valuable members of IT pain management teams. Treatment success requires ongoing monitoring of efficacy and adverse effects, with corresponding adjustments to medication selection and dosing, in addition to good communication among the health care professionals involved in patient care.

Keywords: chronic pain, implantable drug delivery system, morphine, patient education, ziconotide

\section{Plain language summary}

This review article describes an interprofessional approach to intrathecal (IT) therapy delivery for patients with chronic pain, with a focus on physician assistants (PAs), nurse practitioners (NPs), and registered nurses (RNs). These professionals are commonly involved with patient selection, managing patient expectations and goal setting, medication selection and/or administration (dosing, titration, and adverse effect management), outcome assessment, and treatment adjustment, in collaboration with physicians and other health care professionals. Currently, morphine and ziconotide (a nonopioid, selective N-type calcium channel blocker) are the only agents approved by the US Food and Drug Administration for IT analgesia. Treatment success requires ongoing monitoring of efficacy and adverse effects of these agents, with corresponding adjustments to medication selection and dosing, in addition to good communication among the health care professionals involved in patient care. Relevant information on dosing, titration, and adverse effect management of these medications for PAs, NPs, and RNs will contribute to their roles as valuable IT pain management team members.
Correspondence: Jeremy A Adler Pacific Pain Medicine Consultants, 477 North El Camino Real, Suite B30I, Encinitas, CA 92024, USA

Tel +I 7607531104

Mob +16198291430

Fax +I 7609436494

Email jadler@pacificpainmed.com 


\section{Introduction}

The role of physician assistants (PAs), nurse practitioners (NPs), and registered nurses (RNs) in health care is important, with an estimated 201,000 PAs/NPs in clinical practice in the USA in $2013^{1}$ and 2.8 million RNs in the US workforce as of $2010 .^{2}$ An expanded role for PAs/NPs in patient care has been proposed, given the physician shortage anticipated in the USA, particularly in primary care. ${ }^{3}$ PAs are also well suited to specialty care, and $\sim 72 \%$ of certified PAs practice in nonprimary care settings. ${ }^{4}$ PAs, NPs, and RNs provide professional services on many pain management teams in the USA and are taking an increasingly active role. ${ }^{5}$

Chronic refractory pain is a persistent pain of duration $\geq 6$ months that does not adequately respond to, or is associated with intolerable adverse effects from, treatment with standard therapies for pain. ${ }^{6,7}$ A definition of refractory pain for use in evaluating patients as candidates for advanced pain management interventions such as intrathecal (IT) therapy states that "Pain is defined as refractory, regardless of etiology, when 1) multiple evidence-based biomedical therapies used in a clinically appropriate and acceptable fashion have failed to reach treatment goals that may include adequate pain reduction and/or improvement in daily functioning or have resulted in intolerable adverse effects, and when 2) psychiatric disorders and psychosocial factors that could influence pain outcomes have been assessed and appropriately addressed". 8

IT administration delivers analgesic medications directly into the cerebrospinal fluid at the site of action (ie, the dorsal horn of the spinal cord). ${ }^{6,79}$ Advantages of IT therapy may include increased efficacy and decreased systemic medication doses (with an associated reduction in side effects) compared with systemic administration. ${ }^{9}$ Morphine (a mu-opioid receptor agonist) and ziconotide (a nonopioid, selective N-type calcium channel blocker) are approved by the US Food and Drug Administration (FDA) for IT analgesia in the management of patients with chronic refractory pain. ${ }^{7,10,11}$

Pain management is a medical specialty in which PAs, NPs, and RNs serve an important role in patient evaluation, education, and management. ${ }^{5,12}$ The expanding role of PAs/ NPs in pain medicine centers may include initial patient assessment and treatment formulation, medication management, and patient monitoring during follow-up visits (including visits after device implants or other procedures). ${ }^{5}$ Pain management nursing is a recognized specialty, and a certification program is available for eligible RNs. The role of RNs in the management of IT therapy has been formally acknowledged. ${ }^{13-15}$
The purpose of this review is to provide an overview of the practical management of chronic pain with IT therapy using an interprofessional approach (ie, physicians and other health care professionals), with a focus on the contributions of PAs, NPs, and RNs. Any health care professional participating in IT management must have the proper education, experience, and competence to provide services in a safe and high-quality manner.

\section{Methods}

The Medline database was searched using the terms "intrathecal" AND "chronic" AND "pain" in the article title/abstract. Results were refined by adding search terms relevant to the clinical practice of IT therapy including "patient selection, trialing, dosing, morphine, ziconotide, safety, complication, and guidelines". Searches were limited to English-language publications. Abstracts were reviewed to identify publications relevant to the use of an intraprofessional approach to IT therapy for chronic pain management. Treatment guidelines based on review/analysis of research evidence were selected for further consideration.

\section{Patient selection}

IT therapy may be considered for patients with chronic pain of cancer-related or noncancer-related origin. ${ }^{16,17}$ Patients with chronic cancer pain differ from those with chronic noncancer pain in that they may have a poorer prognosis and shorter anticipated life expectancy, different desired IT therapy outcomes (eg, pain relief vs gain of function), various types and locations of cancer pain (eg, metastases), differing approaches to treating comorbidities (eg, radiation therapy for bone metastases), and occurrences of breakthrough pain. ${ }^{18,19}$ Patients with chronic pain of either cancer or noncancer origin may object to the adverse effects of systemic opioids (eg, sedation, nausea, and constipation $)^{20}$ and seek alternate therapeutic options. Thus, evaluation of suitability for IT therapy involves consideration of pain etiology-specific and patient-specific factors. ${ }^{16,21}$

Patient selection for IT therapy is a critical step in the treatment process ${ }^{22}$ and takes into consideration a patient's treatment history, psychological well-being, social support structure, health care coverage, finances, and probability/ capability of adherence with IT therapy requirements. ${ }^{6}$ In the authors' experience, the interprofessional model of addressing the complexities of patients with chronic pain may include the involvement of PAs/NPs/RNs on some teams making recommendations on which patients may be appropriate candidates for IT therapy. Psychological assessment is 
recommended for patients with chronic noncancer pain, while the decision to evaluate patients with chronic cancer pain takes into consideration current disease status (eg, terminal and in remission) and therapeutic goals (eg, pain relief and increased quality of life). ${ }^{18,23}$ Patients who no longer have evidence of malignancy, but experience chronic pain, should receive psychological assessment similar to patients with chronic noncancer pain. ${ }^{18}$ It is recommended that a qualified mental health care professional (eg, clinical psychologist and psychiatrist) perform the assessment. ${ }^{24}$

It is important that candidates for IT therapy receive appropriate treatment for conditions that have been associated with poor outcomes, such as inadequately treated psychopathology (eg, anxiety, depression, and suicidal ideation), cognitive impairment, or active substance abuse. ${ }^{6,22,25}$ For patients with cancer-related pain, counseling to address existential and spiritual issues may be particularly helpful. ${ }^{17,23}$ It is also important that all patients have realistic expectations of IT therapy not only for pain relief but also for the potential impact on daily life. ${ }^{6}$

Patient social support systems, distance to a health care facility, availability of reliable transportation, and insurance coverage are also factors to consider in patients with chronic pain who may receive IT therapy. ${ }^{16,18,21}$ Life expectancy and availability of home health care personnel with sufficient knowledge of IT treatment are additional considerations. ${ }^{18}$ Adequate social support is important for patients with chronic pain receiving IT therapy, ${ }^{6,26}$ as family members and primary caregivers can provide valuable insights regarding the condition of the patient at clinic visits ${ }^{6}$ and aid in monitoring patients. ${ }^{21}$ Patient willingness and ability to comply with IT therapy maintenance is important. The frequency of pump refills may vary with changes in dose, concentration, multiple medication combinations, progressive patient pathology, and tolerance resulting in modifications. ${ }^{6}$ Issues related to treatment cost and insurance reimbursement may pose a barrier to IT therapy for some patients.

A number of comorbidities should be considered in patients with chronic noncancer pain who are candidates for IT therapy, as some conditions may increase the risk of complications, including diabetes (eg, postsurgical infection), anticoagulant therapy (eg, postoperative bleeding), compromised immunity (eg, infection), chronic infection (eg, bacteremia), obstructive sleep apnea (eg, postimplantation respiratory complications), chronic pulmonary disease (eg, respiratory depression), cardiovascular disease (eg, hypotension), and kidney disease (eg, cardiovascular disease). ${ }^{6}$ The decision as to whether any comorbidity presents a contraindication for IT therapy should be made on a caseby-case basis. For patients with certain comorbidities, IT therapy may be appropriate only with specific medications (eg, ziconotide in patients with obstructive sleep apnea or chronic pulmonary disease and opioids in patients with a history of psychosis). ${ }^{21}$

\section{Trialing of IT therapy}

The value of trialing IT therapy is controversial. Historically, trialing of IT therapy has been performed as a means, in theory, to assess efficacy, tolerability, and safety as a part of the decision-making process regarding device implantation and may be necessary to satisfy payer reimbursement requirements. ${ }^{24,27}$ Trialing may also provide an opportunity to clarify patient and provider expectations for and acceptance of the IT route of administration. However, data supporting a correlation between trialing outcome and IT therapy outcome are currently lacking, ${ }^{24}$ and the number of medications routinely administered via IT therapy limits the comprehensiveness of the information that may be derived during a trial. Success of trialing often is defined as a $\geq 50 \%$ decrease from baseline in visual analog scale pain scores without the occurrence of intolerable adverse events; ${ }^{22,24}$ however, there are variations in the criteria used to define a successful trial outcome (eg, pain relief and improvement in functional outcomes). ${ }^{24}$

Trialing methodology (ie, single or multiple injections, continuous infusion in the IT or epidural space) varies and is based on a number of factors, including health care professional preference, health care needs of the patient (eg, availability of trained nursing staff, supplies, and patient condition), and duration of time needed to evaluate IT therapy. ${ }^{18,24,27}$ Weaning of systemic opioids may be considered before initiation of trialing, and improvement or worsening of pain after weaning is an important consideration. ${ }^{24}$ Improvement in pain upon weaning of systemic opioids may be an indication of opioid-induced hyperalgesia $(\mathrm{OIH})$; if eliminating $\mathrm{OIH}$ results in sufficient pain relief, IT pump implantation may not be necessary. ${ }^{24}$ In an attempt to provide compassionate care and adequate pain relief, trialing can be waived in patients with chronic cancer pain with limited life expectancy if they would otherwise be considered suitable candidates for IT therapy. ${ }^{18}$

\section{Patient education}

A critical component to success with IT therapies involves patient education and the establishment of reasonable and realistic expectations. ${ }^{21}$ In many settings, this assignment primarily rests with $\mathrm{PAs} / \mathrm{NPs} / \mathrm{RNs}$, who are also responsible 
for postimplant maintenance and ongoing supportive care. Fundamental education includes explaining that IT therapy is intended to help manage pain but does not treat or cure the underlying condition(s). In addition, it is crucial to convey to patients that pain reduction is an important indicator of treatment success, but that complete resolution of pain is unrealistic and rarely occurs. ${ }^{21}$ We have found it useful for patients to identify specific personal goals for pain management with regard to physical, social, and emotional functioning (eg, walking to mailbox, standing from seated position without assistance, and increased social interactions) and review them with health care professionals to better manage expectations and long-term satisfaction with IT therapy.

In addition, an overview of trialing and implantation procedures should involve discussion of potential complications and risks. Patients receiving IT therapy should understand the size and placement of the IT device ${ }^{6}$ and be aware that implantation may differ from trialing with regard to incisions, cosmetic appearance, medication dosing, use of multimedication regimens, and ability to titrate medication to address tolerability concerns (if present). ${ }^{28}$ Patients with an implanted IT pump should be educated about activities that require modification (eg, carrying their device identification card to justify bypassing airport and store security scanners) or should be avoided (eg, flights at $>13,000$ feet in an unpressurized cabin and hyperbaric chambers). ${ }^{29,30}$ Magnetic resonance imaging (MRI) can also affect IT pump function. ${ }^{29,30}$ Manufacturer recommendations found in the prescriber's information for the specific device should be carefully followed. ${ }^{31,32}$

Additional educational emphasis should include importance of complying with appointments and refills, raising awareness of opioid withdrawal symptoms, providing information regarding the patient's health care team (eg, contact information, who and when to call if specific problems arise, and what information to provide to team members) and IT pump (eg, pump type and specifications, drug concentration and dosing, and refill information), and advising the health care team about changes in patient contact information. ${ }^{28,29}$ Patients should also understand the importance of activity pacing, as risk for injury may increase as pain is controlled. Analgesic therapy may not only reduce pathological nociception but also may mask pain that would signal the patient to cease activities that could lead to injury.

\section{IT pump considerations}

An IT drug delivery device comprised pump reservoir, mechanical infusion pump, and IT catheter (Figure 1). ${ }^{27}$

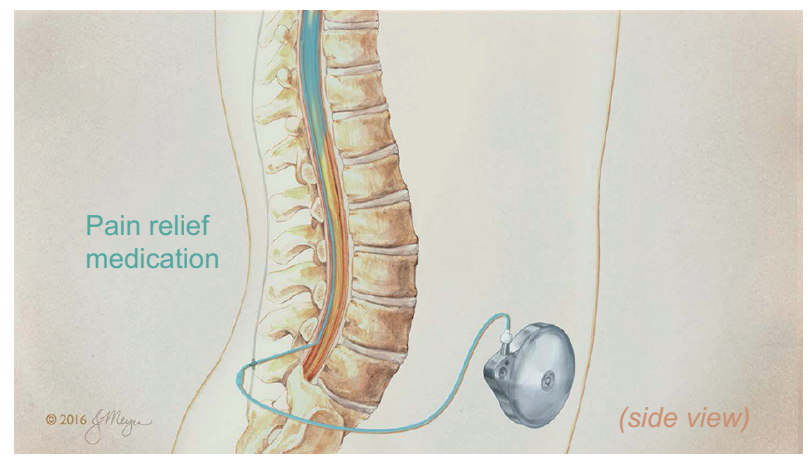

Figure I IT device with mechanical infusion pump and IT catheter. Note: Illustration (C) 2016 Jackie Meyer.

Abbreviation: IT, intrathecal.

Programmable IT pumps such as the SynchroMed ${ }^{\circledR}$ II (Medtronic, Minneapolis, MN, USA) and the Prometra ${ }^{\circledR}$ and Prometra ${ }^{\circledR}$ II (Flowonix, Mt Olive, NJ, USA) regulate the flow rate, allowing externally programmable variations in dosing. ${ }^{27,32,33}$

On some pain management teams, PAs, NPs, and RNs are responsible for managing the medical and technical aspects of IT therapy and addressing therapy system complications. After IT device implant, dose titration based on the patient's response to treatment may necessitate multiple appointments, especially during initial postoperative months. ${ }^{34}$ IT pump refills generally occur between 1 and 6 months and are dependent on reservoir volume; dose, concentration, and stability of the IT therapy; and drug expiration date..$^{29,33}$ Patients with appointments for medication titration and/or pump refill should undergo a pain assessment and physical examination, and NPs/PAs/RNs should determine if dosing or therapy changes are necessary or advisable. ${ }^{16,29}$ Availability of, and ease of communication with, the physician is critical in pain practices where RNs are performing treatment assessment and adjustment.

When refilling pumps, $\mathrm{PAs} / \mathrm{NPs} / \mathrm{RNs}$ should confirm that the drug, dosing, and flow rate are accurate, that aseptic technique is used to maintain sterility of the pump reservoir and catheter, and that the reservoir, rather than the pump pocket, receives the drug. ${ }^{33,35}$ The ability to diagnose and detect a pocket fill is of particular importance. ${ }^{35,36}$ The process for refilling programmable IT pumps is described in Table $1 .^{33}$ Fluoroscopy or ultrasonography may be used to guide PAs/ NPs/RNs during pump refills. ${ }^{37}$ These techniques provide visualization and, thus, improved localization of the pumpaccess port compared with template-guided approaches, ${ }^{38-40}$ although use of the template is generally sufficient in the clinical experience of the authors. Ultrasound-guided pump 
Table I Procedure for refilling IT pumps

Items needed for refilling IT pumps:

- Kit from IT device manufacturer containing access needle and template

Step I:

- Clean skin at site of IT pump using aseptic technique

Step 2:

- Place template provided in kit over the IT pump to detect site of pump reservoir fill port, or, alternatively, use ultrasound or fluoroscopy

- Fill port located centrally within IT pump

Step 3:

- Insert the access needle provided in the kit through the skin and self-sealing silicone septum located in the middle of the fill port

Step 4:

- Aspirate any remaining drug from the reservoir

- Assess proper pump function by comparing the volume of remaining drug with the calculated volume that should remain based on the programmed flow rate

Step 5:

- Refill the pump by injecting the appropriate volume and concentration of drug through the pump reservoir fill port - Utilize fluoroscopy or ultrasound, if needed

Step 6:

- Reprogram the IT pump with the new volume and/or concentration of drug

Note: Data from Bottros MM and Christo PJ.3

Abbreviation: IT, intrathecal.

access, while not as well established as fluoroscopic guidance in IT pump management, has shown improvement in image quality in recent years and has the advantage of being cost-effective and radiation-sparing. ${ }^{41,42}$ At each refill, comparison of drug volume aspirated from the reservoir with expected volume (based on the programmed flow rate) provides a general assessment of proper pump function; ${ }^{33,36}$ ultrasound may be used after refill to examine for changes in the appearance of the pump pocket that might indicate a possible pocket fill. ${ }^{37}$

\section{Medication selection and dosing}

In many practices, decisions regarding selection and dosing of IT medication are made by an interprofessional medical team that includes physicians, PAs, NPs, and RNs. Similar to interventional pain physicians, PAs and NPs generally adhere to the Polyanalgesic Consensus Conference (PACC) guidelines for IT drug selection. ${ }^{35}$ Morphine and ziconotide are the only medications approved by the FDA for IT analgesia. Both are recommended by the PACC as first-line IT therapy for patients with pain that is neuropathic or nociceptive, localized or diffuse, and cancer related or noncancer related. ${ }^{35}$ Unless contraindicated (eg, by patient history of psychosis), ziconotide is recommended ahead of opioids in patients with noncancer pain. ${ }^{35}$ The off-label use of other agents is common in IT therapy, based on evidence-based publications and practitioner experience, and some of these agents (eg, bupivacaine, hydromorphone, fentanyl, and clonidine) are included in the PACC recommendations. ${ }^{35}$

Morphine was approved as IT therapy for patients with chronic pain based primarily on efficacy findings from retrospective and prospective noncontrolled studies. ${ }^{35}$ The decision to administer IT morphine should include an assessment of the patient's previous experience with systemic opioids (eg, $\mathrm{OIH}$ and opioid-related adverse events $)^{21,35,43}$ and other conditions that may affect the safe use of IT morphine, including chronic pulmonary disease and obstructive sleep apnea. ${ }^{6}$ Recommended dosing of IT morphine starts at $0.1-0.5 \mathrm{mg} /$ day (in patients without tolerance to opioids), with a maximum of $15 \mathrm{mg} /$ day. ${ }^{35}$ In patients who have not received adequate pain relief despite escalating doses of systemic opioids, change in both mechanism of action and route of administration to a nonopioid IT medication may be warranted. ${ }^{16}$ Age may also be a factor in the decision to use opioid or nonopioid therapy. ${ }^{6,44}$ Older patients are at increased risk of adverse events (eg, cognitive impairment, dizziness, and respiratory depression) with IT opioids; ${ }^{6}$ whereas younger patients ( $18-50$ years) may have greater risk of developing tolerance to opioids compared to those aged 50 years and older. ${ }^{44}$

The efficacy of ziconotide was demonstrated in three randomized, placebo-controlled clinical trials of patients with severe, chronic pain. ${ }^{45-47}$ The decision to administer IT ziconotide should include an assessment of psychiatric history, as IT ziconotide is contraindicated in patients with a history of psychosis. ${ }^{11}$ In an analysis across ziconotide clinical trials, $22(1.6 \%)$ of the 1351 ziconotide-treated patients experienced a psychosis event; these events were considered related to ziconotide by the investigator in 10 $(0.7 \%)$ patients. ${ }^{48}$ Neuropsychiatric adverse events may not present until months after IT ziconotide is initiated; $;{ }^{36}$ thus, monitoring for psychiatric symptoms (eg, mental confusion and hallucinations) remains important for the duration of therapy. Initiating IT ziconotide with low doses and titrating slowly with incremental, small, weekly dose increases may minimize the risk of neuropsychiatric symptoms, ${ }^{21,36}$ an important factor to consider when evaluating the results of a trial of IT ziconotide. The recommended starting dose for IT ziconotide, according to the most recent PACC guidelines, is $0.5-1.2 \mu \mathrm{g} / \mathrm{day}$ (to $2.4 \mu \mathrm{g} / \mathrm{day}$ per product labeling), with upward titration of $\leq 2.4 \mu \mathrm{g} /$ day at intervals of $\leq 2-3$ times per week, to a maximum of $19.2 \mu \mathrm{g} /$ day. ${ }^{11,35}$ Data from an interim analysis of the Patient Registry of Intrathecal Ziconotide Management suggest that greater benefits may be obtained 
when ziconotide is used as first-line IT therapy rather than as a second-or-later agent in pump. ${ }^{49}$

Novel dosing strategies have been developed to enhance the effectiveness of IT therapy and reduce the incidence and severity of adverse effects. ${ }^{50}$ The SynchroMed II and Prometra II programmable pumps enable patient-controlled bolus doses of IT medications within clinician-programmed limits. ${ }^{51,52}$ Although the manufacturer's information for the SynchroMed accessory (the myPTM ${ }^{\circledR}$ Personal Therapy Manager; Medtronic) states that the use of ziconotide with this device is contraindicated, ${ }^{53}$ the rationale for supplemental bolus dosing of IT ziconotide is supported by research data and clinical experience. ${ }^{50} \mathrm{~A}$ dosing strategy for the use of patient-controlled bolus doses to supplement continuous infusion of IT medication has been evaluated in a case series (patients receiving ziconotide with or without IT hydromorphone). ${ }^{50,54}$ Another dosing strategy involves the use of the flex-mode feature of the SynchroMed II pump, which permits adding scheduled bolus doses, as programmed by the clinician, to the continuous infusion. ${ }^{55} \mathrm{~A}$ flex-dosing strategy has been evaluated in a case series of patients receiving IT ziconotide. ${ }^{50,56}$ Efficacy and safety outcomes observed in these cases are promising; further evaluation in rigorous, controlled studies seems to be warranted. ${ }^{50,54,56}$

\section{Outcome monitoring}

\section{Pain assessment}

Pain evaluation may include verbal and nonverbal communication: ${ }^{57}$ pain intensity (eg, numeric and visual pain rating scales; Figure 2A-D), ${ }^{58-63}$ time of occurrence, duration (eg, continuous and intermittent), location (eg, localized and radiating), pain quality (eg, sharp and achy), and any additional

A

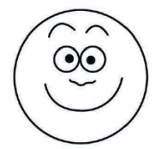

0

No

hurt

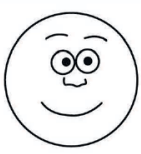

2

Hurts little bit

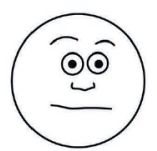

4

Hurts little more

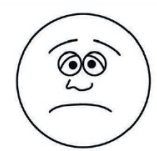

6

Hurts even more

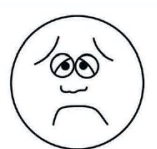

8

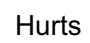
whole lot

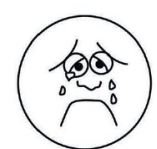

10

Hurts worst

B

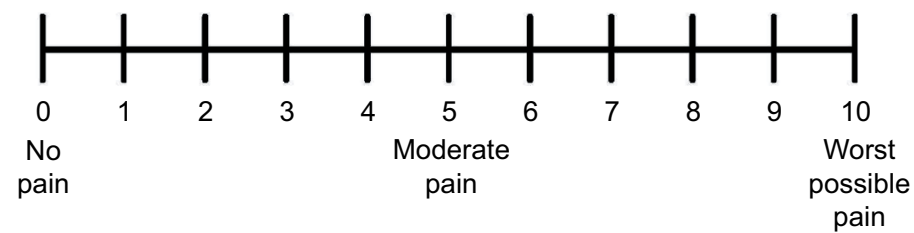

C
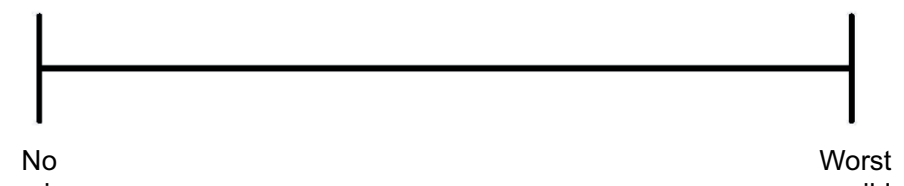

pain possible

D

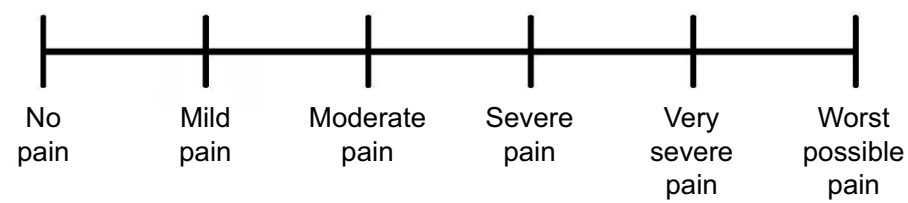

Figure 2 Pain rating scales.

Notes: (A) Wong-Baker FACES ${ }^{\circledR}$ pain rating scale; Wong-Baker FACES Foundation (2016). Wong-Baker FACES ${ }^{\circledR}$ Pain Rating Scale. Retrieved April I8, 2017 with permission from http://www. WongBakerFACES.org. ${ }^{58}$ (B) 0-10 numeric pain rating scale; created with data from Breivik $\mathrm{H}$, et al. ${ }^{59}$ and Herr K, et al. ${ }^{60}$ (C) Visual analog scale; created with data from Breivik H, et al. ${ }^{59}$; Paice JA and Cohen FL. ${ }^{61}$; and Jensen MP, et al. ${ }^{62}$ (D) Verbal pain intensity scale; created with data from Breivik H, et al. ${ }^{59}$; and Breivik EK, et al. ${ }^{63}$ 
symptoms (eg, nausea). ${ }^{64}$ Because the experience of pain is subjective, the use of standardized assessment measures is important. ${ }^{65}$ Advantages of numeric pain rating scales include ease of use, high compliance, and sensitivity to treatment effects. ${ }^{65,66}$ When evaluating pain in patients with cognitive impairment or an inability to communicate, the practitioner may rely more on clinical expertise and caregivers than on patient self-evaluation, ${ }^{67,68}$ which is another critical reason for evaluating the patient's social support system prior to IT device implantation. In addition, standardized, observational assessment tools have been developed for evaluating pain in patients unable to use numeric/visual rating scales, including patients with cognitive impairment, critically ill patients, and children. ${ }^{69-71}$

In patients who demonstrate an inadequate analgesic response to IT therapy, dose titration and/or altering the dosing schedule are typically the first treatment options to consider. ${ }^{16,34}$ When lack of efficacy with no adverse events is observed in a patient despite dose increases, the pump should be investigated for malfunctions. ${ }^{16,34}$ Adding another IT medication to the treatment regimen or switching to a different IT agent may be considered for patients who do not obtain adequate pain relief with appropriate dose titration. ${ }^{16,34}$

\section{Concomitant IT and non-IT medications}

Use of concomitant IT and non-IT medication is common in patients with chronic pain. ${ }^{72}$ Nonessential medications (particularly central nervous system [CNS]-active drugs) should be discontinued, if possible, especially during trialing and at the time of device implantation. ${ }^{34}$ Careful monitoring of patients receiving therapies that affect the CNS (eg, sedatives, non-IT opioids, antidepressants, and antihistamines) is critical. ${ }^{34}$ In patients receiving IT ziconotide, CNS effects may occur with concomitant treatment with antiepileptic agents, neuroleptic agents, sedatives, or diuretics. ${ }^{11}$

Patients with chronic cancer pain receiving IT therapy for pain management may also receive chemotherapy, thus coordination of care should occur with the patient's oncologist. ${ }^{73}$ Radiation therapy is used palliatively in patients with cancer, but because pain relief may not occur for several days, concurrent IT therapy may be an option for some patients. ${ }^{73}$ Patients with chronic cancer pain receiving IT therapy for pain management may experience breakthrough pain, which may require rescue treatment with immediate-release oral opioids $^{73}$ or use of the patient-controlled bolus device available with some IT pumps and medications. ${ }^{17}$ The use of oral opioids in patients receiving IT therapy for noncancerrelated pain is a matter of some debate. The PACC guidelines recommend reduction or elimination of systemically delivered opioids as a goal of IT therapy. ${ }^{24}$ For patients with suboptimal response to IT monotherapy, adjuvant treatment with oral opioids is one option, although combination IT therapy may provide a reasonable alternative. ${ }^{35}$

Adverse effects of IT therapy can often be managed with concomitant non-IT therapy, including antiemetics for nausea and vomiting; naloxone for pruritus; peripherally acting opioid antagonists, stool softeners, or laxatives for constipation; diuretics for edema; and naloxone or nalbuphine for respiratory depression. ${ }^{34}$

\section{Adverse events related to IT therapy}

A variety of complications may arise, including those related to the IT pump itself (eg, mechanical failure), pump pocket fills, medication preparation and/or programing errors, and adverse effects related to IT device implantation (eg, postdural puncture headache, bleeding, and infection). ${ }^{23,33}$ IT pump mechanical malfunction (Table 2) ${ }^{18,29,33}$ may result in complications related to underdosing (eg, decrease in or loss of analgesia and symptoms of opioid withdrawal) or overdosing (eg, respiratory depression and possibly death due to opioid overdose)..$^{29,33,74}$

Adverse effects associated with the use of IT opioids include respiratory depression (potentially the most serious side effect), endocrinopathy, constipation, nausea, vomiting, urinary retention, peripheral edema, and pruritus. ${ }^{34,75}$ In a study of long-term IT opioid therapy, hypogonadotropic hypogonadism was observed in the large majority of patients and decreased libido was common in women and almost ubiquitous in men. ${ }^{76}$ Pretreatment evaluation and periodic monitoring of neuroendocrine function are recommended for patients receiving IT opioids..$^{34,36}$ In addition, patients receiving IT therapy with opioids are at risk for the formation of noninfectious inflammatory masses, or granulomas, at the catheter tip..$^{33,36,77,78} \mathrm{~A}$ decrease in or loss of analgesia with the onset of new neurologic symptoms or new-onset back pain in the area of the spine near the catheter tip location may indicate granuloma formation. ${ }^{18,29,36}$ Evaluation for suspected granulomas includes MRI, computed tomography (CT), CT myelogram, or side-port studies followed by CT. ${ }^{29,36}$ Granulomas can cause spinal cord compression, which may result in neurological complications ranging in severity from loss of analgesia to paraplegia..$^{29,79}$

IT ziconotide has been associated with dizziness, confusion, impaired memory, ataxia, abnormal gait, somnolence, asthenia, headache, nausea, and vomiting. ${ }^{80}$ Patients may also experience dysesthesia, blurred vision, confusion, 
Table 2 Potential mechanical IT pump and catheter malfunctions and complications

\begin{tabular}{|c|c|c|}
\hline Pump malfunction & Description & Potential complications \\
\hline $\begin{array}{l}\text { Catheter pump } \\
\text { misconnection }\end{array}$ & $\begin{array}{l}\text { Usually occurs immediately after implantation but may be } \\
\text { delayed }\end{array}$ & $\begin{array}{l}\text { Leakage of IT therapy } \\
\text { Opioid withdrawal symptoms } \\
\text { Loss of analgesia }\end{array}$ \\
\hline $\begin{array}{l}\text { Loss of pump } \\
\text { propellant }\end{array}$ & Altered rate of drug delivery & $\begin{array}{l}\text { Drug overdose or underdose (eg, opioid withdrawal } \\
\text { symptoms and loss of analgesia) }\end{array}$ \\
\hline $\begin{array}{l}\text { Gear shaft wear and } \\
\text { motor stall }\end{array}$ & Reduced infusion of IT therapy & $\begin{array}{l}\text { Withdrawal symptoms } \\
\text { Decrease in or loss of analgesia }\end{array}$ \\
\hline $\begin{array}{l}\text { Leakage of } \\
\text { administered agent }\end{array}$ & $\begin{array}{l}\text { Occurs at pump-catheter connection and may result from } \\
\text { catheter kinking, or catheter damage caused by punctures } \\
\text { by needle sticks or retractors used during implantation }\end{array}$ & $\begin{array}{l}\text { Opioid withdrawal symptoms } \\
\text { Loss of analgesia }\end{array}$ \\
\hline Catheter displacement & Leakage of CSF & Local hygroma \\
\hline Catheter kinking & $\begin{array}{l}\text { Occurs at any point from the pump along the length of } \\
\text { the catheter }\end{array}$ & $\begin{array}{l}\text { Difficulty aspirating CSF and injecting drug(s) into the pump } \\
\text { Leakage of IT therapy } \\
\text { Opioid withdrawal symptoms } \\
\text { Loss of analgesia }\end{array}$ \\
\hline Catheter tip granuloma & $\begin{array}{l}\text { Decrease in or loss of analgesia with onset of new } \\
\text { neurologic symptoms } \\
\text { Evaluation includes MRI or computed tomography with } \\
\text { myelography (when MRI contraindicated) }\end{array}$ & $\begin{array}{l}\text { Spinal cord compression, possibly resulting in paraplegia, and, } \\
\text { in some patients, death }\end{array}$ \\
\hline
\end{tabular}

Notes: Data from Deer TR, et al. ${ }^{18}$; Upadhyay SP and Mallick PN. ${ }^{29}$; and Bottros MM and Christo PJ. ${ }^{33}$

Abbreviations: CSF, cerebrospinal fluid; IT, intrathecal; MRI, magnetic resonance imaging.

speech impairment, psychological symptoms (eg, anxiety, depression, and panic attacks), and peripheral edema ${ }^{80}$ IT ziconotide has not been associated with the development of granulomas, respiratory depression, or withdrawal symptoms. ${ }^{74} \mathrm{PAs}$, NPs, and RNs must be hypervigilant for potential complications. Early detection and intervention are necessary to avoid IT system and medication complications.

\section{Interprofessional pain medicine team approach}

In addition to management by an interprofessional pain medicine team, involvement of professionals from other disciplines (eg, pharmacists, psychologists, and physical therapists) is also beneficial. Interprofessional/multidisciplinary approaches to the management of chronic pain have been associated with improvements in quality of life, daily functionality, and pain relief. ${ }^{23,81}$

PAs, NPs, and RNs are often involved with patient selection, patient education and managing expectations of IT therapy, overseeing drug/dose selection, performing pump refills, monitoring for complications, and communicating with patients/caregivers between visits. Physicians often conduct the IT medication trial, surgical implantation of the IT device, procedural work-up of device malfunctions such as dye studies, and surgical revision of hardware complications or replacement when hardware reaches the end of usable life. Nursing and support staff often act as patient advocates, as the primary point of contact for patients. ${ }^{26,57}$
An interprofessional and multidisciplinary approach to pain management leverages the unique and specialized skill sets and experiences of a diverse team compared with pain management decisions driven by a single health care professional. Benefits of multidisciplinary treatment have been demonstrated in the overall management of chronic pain. ${ }^{82,83}$ Although the advantages of an interprofessional approach to IT therapy are less well studied, the goals of the team model include appropriate patient selection, improved patient care, better patient adherence to therapy, improved clinical outcomes, good economic value, and enhanced patient satisfaction.

Responsibilities for optimal management of patients with chronic pain occur at the level of the patient, health care team, and within the health system. The role of patients and their families in the team approach cannot be overlooked, as patients are responsible for providing accurate contact information to their health care professionals, complying with scheduled IT therapy refill appointments, and accurately reporting pain or other symptoms (including improvements or decreases in daily function) and adverse effects. ${ }^{6}$ Support staff, such as medical assistants and nonclinical personnel, fulfill specific responsibilities (eg, patient scheduling, ordering of compounded medications, and insurance verification/ authorization) and coordinate with other team members to provide quality care to patients receiving IT therapy.

Management of IT therapy necessitates communication between primary care providers (PCPs) and medical 
specialists, as well as physical therapists, mental and behavioral health specialists, radiologists, and emergency medicine clinicians. Patients may present with comorbid conditions unrelated to chronic pain (eg, diabetes, hypertension, and cancer), which should be conveyed to the PCP or appropriate specialist. Patients also may seek care for conditions unrelated to chronic pain (eg, acute trauma and medical emergency), involving other health care systems (eg, emergency department and inpatient services) that may require information about handling of the IT pump. It may be necessary to educate other health care professionals regarding the differentiation of IT therapy-related complications from presentation of symptoms that are entirely unrelated to the IT device and warrant the standard medical workup.

Ongoing quality improvement and education processes should be in place for pain medicine team members to share medical errors and develop strategies to ensure positive outcomes in the future. ${ }^{84}$ Pain management team members should be aware of policies and procedures related to patient care, including, but not limited to, roles of specific team members. ${ }^{84}$ Regular rehearsals addressing potential problems that may arise in the care of patients receiving IT therapy (eg, procedural errors and adverse events) can reinforce communication and coordination of roles among the interprofessional and multidisciplinary teams. ${ }^{84}$ PAs, NPs, and RNs should regularly participate in continuing education opportunities to update and remain current in their knowledge of pain management practices. $^{84}$

\section{Conclusion}

IT therapy is an effective treatment option for appropriately selected patients with refractory chronic pain. As a part of interprofessional teams, PAs, NPs, and RNs are responsible for many aspects of IT therapy, including patient education, assessment, and postimplant treatment management. Treatment success requires ongoing monitoring of efficacy and adverse events, with corresponding adjustments to IT medication selection and dosing, as well as the use of concomitant oral medications. Communication with the physicians and other health care professionals involved in patient care is essential for the optimal management of patients receiving IT therapy.

\section{Acknowledgments}

The authors thank Nancy Holland, PhD, and Sophie Bolick, PhD, of Synchrony Medical Communications, LLC, for providing writing support and Synchrony Medical
Communications for editorial assistance in formatting, proofreading, copy editing, and fact checking, which was funded by Jazz Pharmaceuticals in accordance with Good Publication Practice (GPP3) guidelines (http://www.ismpp. org/gpp3). Jazz Pharmaceuticals also reviewed the manuscript. Although Jazz Pharmaceuticals was involved in the review of the manuscript, the content of the manuscript, the ultimate interpretation, and the decision to submit for publication in the Journal of Pain Research were determined by the authors independently.

\section{Author contributions}

All authors were involved in the study concept, drafted/ revised the manuscript for important intellectual content, approved the final version to be published, and agreed to be accountable for all aspects of the work.

\section{Disclosure}

JAA reports serving as a speaker or consultant for AstraZeneca, Daiichi Sankyo Company, Limited, Depomed, Kaléo, Inc., Egalet, Inc., Millennium Labs, Pernix, St. Jude Medical Neuromodulation Systems, and Quest Diagnostics. NL reports serving on the speakers' bureau for Azur Pharma Inc. The authors report no other conflicts of interest in this work.

\section{References}

1. Hooker RS, Brock DM, Cook ML. Characteristics of nurse practitioners and physician assistants in the United States. J Am Assoc Nurse Pract. 2016;28(1):39-46.

2. US Department of Health and Human Services Health Resources and Services Administration. The U.S. Nursing Workforce: Trends in Supply and Education. Rockville, MD: Health Resources \& Services Administration; 2013.

3. Bodenheimer TS, Smith MD. Primary care: proposed solutions to the physician shortage without training more physicians. Health Aff (Millwood). 2013;32(11):1881-1886.

4. National Commission on Certification of Physician Assistants. 2015 Statistical Profile of Certified Physician Assistants, An Annual Report of the National Commission on Certification of Physician Assistants. Johns Creek, GA: National Commission on Certification of Physician Assistants; 2016.

5. Schneider J. Emerging role of NPs and PAs in pain management. Pract Pain Manag. 2008;8(5):23-27.

6. Deer TR, Smith HS, Cousins M, et al. Consensus guidelines for the selection and implantation of patients with noncancer pain for intrathecal drug delivery. Pain Physician. 2010;13(3):E175-E213.

7. Hayek SM, Deer TR, Pope JE, Panchal SJ, Patel VB. Intrathecal therapy for cancer and non-cancer pain. Pain Physician. 2011;14(3):219-248.

8. Deer TR, Caraway DL, Wallace MS. A definition of refractory pain to help determine suitability for device implantation. Neuromodulation 2014; 17:711-715.

9. Pope JE, Deer TR. Intrathecal drug delivery for pain: a clinical guide and future directions. Pain Manag. 2015;5(3):175-183.

10. Morphine sulfate injection [package insert]. Lake Forest, IL: Hospira, Inc.; 2004.

11. Prialt (ziconotide) solution, intrathecal infusion [package insert]. Palo Alto, CA: Jazz Pharmaceuticals, Inc.; 2013 
12. Courtenay M, Carey N. The impact and effectiveness of nurse-led care in the management of acute and chronic pain: a review of the literature. J Clin Nurs. 2008;17(15):2001-2013.

13. Pasero C, Eksterowicz N, Primeau M, Cowley C. Registered nurse management and monitoring of analgesia by catheter techniques: position statement. Pain Manag Nurs. 2007;8(2):48-54.

14. American Society of Anesthesiologists. Statement on the Role of Registered Nurses in the Management of Continuous Regional Analgesia. Washington, DC: American Society of Anesthesiologists; 2013.

15. New York State Board of Nursing [webpage on the Internet]. Intrathecal Pump Management by Registered Nurses. 2011. Available from: http:// www.op.nysed.gov/prof/nurse/nurse-iv-intrathecal-pump.htm. Accessed January 13, 2017.

16. Pope JE, Deer TR, Bruel BM, Falowski S. Clinical uses of intrathecal therapy and its placement in the pain care algorithm. Pain Pract. 2016;16(8):1092-1106.

17. Bruel BM, Burton AW. Intrathecal therapy for cancer-related pain. Pain Med. 2016;12(12):2404-2421.

18. Deer TR, Smith HS, Burton AW, et al. Comprehensive consensus based guidelines on intrathecal drug delivery systems in the treatment of pain caused by cancer pain. Pain Physician. 2011;14(3):E283-E312.

19. Cipta AM, Pietras CJ, Weiss TE, Strouse TB. Cancer-related pain management in clinical oncology. J Community Support Oncol. 2015;13(10):347-355.

20. Benyamin R, Trescot AM, Datta S, et al. Opioid complications and side effects. Pain Physician. 2008;11(2 suppl):S105-S120.

21. Saulino M, Kim PS, Shaw E. Practical considerations and patient selection for intrathecal drug delivery in the management of chronic pain. $J$ Pain Res. 2014;7:627-638.

22. Kim D, Saidov A, Mandhare V, Shuster A. Role of pretrial systemic opioid requirements, intrathecal trial dose, and non-psychological factors as predictors of outcome for intrathecal pump therapy: one clinician's experience with lumbar postlaminectomy pain. Neuromodulation. 2011;14(2):165-175.

23. Deer T, Winkelmuller W, Erdine S, Bedder M, Burchiel K. Intrathecal therapy for cancer and nonmalignant pain: patient selection and patient management. Neuromodulation. 1999;2(2):55-66.

24. Deer TR, Hayek S, Pope JE, et al. The Polyanalgesic Consensus Conference (PACC): recommendations for trialing of intrathecal drug delivery infusion therapy. Neuromodulation. 2017;20(2):133-154.

25. Krames ES, Olson K. Clinical realities and economic considerations: patient selection in intrathecal therapy. J Pain Symptom Manage. 1997;14(3 suppl):S3-S13.

26. Kress HG, Aldington D, Alon E, et al. A holistic approach to chronic pain management that involves all stakeholders: change is needed. Curr Med Res Opin. 2015;31(9):1743-1754.

27. Bolash R, Mekhail N. Intrathecal pain pumps: indications, patient selection, techniques, and outcomes. Neurosurg Clin $\mathrm{N} \mathrm{Am}$. 2014;25:735-742.

28. Deer TR, Prager J, Levy R, et al. Polyanalgesic Consensus Conference2012: recommendations on trialing for intrathecal (intraspinal) drug delivery: report of an interdisciplinary expert panel. Neuromodulation. 2012;15(5):420-435.

29. Upadhyay SP, Mallick PN. Intrathecal drug delivery system (IDDS) for cancer pain management: a review and updates. Am J Hosp Palliat Care. 2012;29(5):388-398.

30. The British Pain Society [webpage on the Internet]. Intrathecal Drug Delivery for the Management of Pain and Spasticity in Adults; Recommendations for Best Clinical Practice. 2015. Available from: https:// www.britishpainsociety.org/static/uploads/resources/files/itdd_2015_ pro_v3.pdf. Accessed October 11, 2017.

31. SYNCHROMED ${ }^{\circledR}$ ISOMED $^{\circledR}$ Implantable Infusion Systems [package insert]. Minneapolis, MN: Medtronic, Inc.; 2016.

32. Prometra ${ }^{\circledR}$ II programmable pump for use with intrathecal catheter [package insert]. Mount Olive, NJ: Flowonix Medical Inc.; 2012.

33. Bottros MM, Christo PJ. Current perspectives on intrathecal drug delivery. J Pain Res. 2014;7:615-626.
34. Prager J, Deer T, Levy R, et al. Best practices for intrathecal drug delivery for pain. Neuromodulation. 2014;17(4):354-372.

35. Deer TR, Pope JE, Hayek S, et al. The Polyanalgesic Consensus Conference (PACC): recommendations on intrathecal drug infusion systems best practices and guidelines. Neuromodulation. 2017;20(2):96-132.

36. Deer TR, Pope JE, Hayek S, et al. The Polyanalgesic Consensus Conference (PACC): recommendations for intrathecal drug delivery: guidance for improving safety and mitigating risks. Neuromodulation. 2017;20(2):155-176.

37. McGlothlen $\mathrm{G}$. The use of interventional ultrasound for pump reservoir refills by the allied health professional. NANS Newslett. 2014;9(3):6-7.

38. Maino P, Koetsier E, Perez RS. The accuracy of template-guided refill technique of intrathecal pumps controlled by fluoroscopy: an observational study. Neuromodulation. 2015;18(5):428-432.

39. Gofeld M, McQueen CK. Ultrasound-guided intrathecal pump access and prevention of the pocket fill. Pain Med. 2011;12(4):607-611.

40. Saulino M, Gofeld M. "Sonology" of programmable intrathecal pumps. Neuromodulation. 2014;17(7):696-698. discussion 698.

41. Gofeld M. Ultrasonography in pain medicine: opening the third eye. Pain Clin Updates. 2012;20(4):1-7.

42. Kothari K, Sahu DK. Ultrasonography versus fluoroscopy in modern pain management. Ind J Pain. 2016;30:71-76.

43. Walker MJ, Webster L. Opioid-induced hyperalgesia and monotherapy intrathecal ziconotide: experience with four cases. J Pain Manag. 2013;6(3):257-264.

44. Hayek SM, Veizi IE, Narouze SN, Mekhail N. Age-dependent intrathecal opioid escalation in chronic noncancer pain patients. Pain Med. 2011;12(8):1179-1189.

45. Rauck RL, Wallace MS, Leong MS, et al. A randomized, double-blind, placebo-controlled study of intrathecal ziconotide in adults with severe chronic pain. J Pain Symptom Manage. 2006;31(5):393-406.

46. Wallace MS, Charapata SG, Fisher R, et al. Intrathecal ziconotide in the treatment of chronic nonmalignant pain: a randomized, double-blind, placebo-controlled clinical trial. Neuromodulation. 2006;9(2):75-86.

47. Staats PS, Yearwood T, Charapata SG, et al. Intrathecal ziconotide in the treatment of refractory pain in patients with cancer or AIDS: a randomized controlled trial. JAMA. 2004;291(1):63-70.

48. Caraway D, Saulino MF, Kim P, Hockett S, Alvarez-Horine S. Characterization of psychotic events in patients on intrathecal ziconotide for severe chronic pain. Presented at: 17th Annual Meeting of North American Neuromodulation Society; December 5-8; 2013; Las Vegas, NV.

49. Deer T, Rauck R, Caraway D, et al. Effectiveness and safety of intrathecal ziconotide as the first agent in pump for adult patients with severe chronic pain [abstract 193]. Presented at: American Academy of Pain Medicine 32nd Annual Meeting; February 18-21; 2016; Palm Springs, CA.

50. McDowell GC, Pope JE. Intrathecal ziconotide: dosing and administration strategies in patients with refractory chronic pain. Neuromodulation. 2016;19(5):522-532.

51. Medtronic Inc. [webpage on the Internet]. Personal Therapy Manager Patient Manual. 2007. Available from: http://www.medtronic.com/content/dam/medtronic-com-m/mdt/neuro/documents/myptm-8835-patmanual.pdf. Accessed May 15, 2017.

52. Flowonix Medical Inc [webpage on the Internet]. Flowonix Medical Inc., announces FDA approval of new product [press release]. 2015. Available from: http://www.prnewswire.com/news-releases/flowonixmedical-inc-announces-fda-approval-of-new-product-300125380.html. Accessed October 11, 2017.

53. Medtronic Inc [webpage on the Internet]. SYNCHROMED II Drug Infusion System Brief Statement. 2016. Available from: http://www. medtronic.com/us-en/healthcare-professionals/therapies-procedures/ neurological/targeted-drug-delivery/indications-safety-warnings/briefstatement.html. Accessed May 15, 2017.

54. McDowell GC. Use of the personal therapy manager with Prialt ${ }^{\circledR}$ (ziconotide intrathecal infusion) for patient-controlled analgesia: case series. Presented at: 14th Annual Meeting of the North American Neuromodulation Society; December 2-5; 2010; Las Vegas, NV. 
55. Medtronic Inc. [webpage on the Internet]. $\mathrm{N}^{\text {'Vision }}{ }^{\mathbb{E}}$ Clinician Programmer with Software. 2016. Available from: http://manuals.medtronic. com/wcm/groups/mdtcom_sg/@emanuals/@era/@neuro/documents/ documents/contrib_240051.pdf. Accessed May 15, 2017.

56. Pope JE, Deer TR. Intrathecal pharmacology update: novel dosing strategy for intrathecal monotherapy ziconotide on efficacy and sustainability. Neuromodulation. 2015;18(5):414-420.

57. Blondal K, Halldorsdottir S. The challenge of caring for patients in pain: from the nurse's perspective. J Clin Nurs. 2009;18(20):2897-2906.

58. Wong-Baker FACES Foundation. Wong-Baker ${ }^{\odot}$ Pain Rating Scale. Oklahoma City, OK: Wong-Baker FACES Foundation; 2016.

59. Breivik H, Borchgrevink PC, Allen SM, et al. Assessment of pain. $\mathrm{Br}$ J Anaesth. 2008;101(1):17-24.

60. Herr K, Spratt KF, Garand L, Li L. Evaluation of the Iowa pain thermometer and other selected pain intensity scales in younger and older adult cohorts using controlled clinical pain: a preliminary study. Pain Med. 2007;8(7):585-600.

61. Paice JA, Cohen FL. Validity of a verbally administered numeric rating scale to measure cancer pain intensity. Cancer Nurs. 1997;20(2): 88-93.

62. Jensen MP, Karoly P, Braver S. The measurement of clinical pain intensity: a comparison of six methods. Pain. 1986;27(1):117-126.

63. Breivik EK, Bjornsson GA, Skovlund E. A comparison of pain rating scales by sampling from clinical trial data. Clin J Pain. 2000;16(1):22-28.

64. Haugh KH. Head-to-toe: organizing your baseline patient physical assessment. Nursing. 2015;45(12):58-61.

65. Hjermstad MJ, Fayers PM, Haugen DF, et al. Studies comparing numerical rating scales, verbal rating scales, and visual analogue scales for assessment of pain intensity in adults: a systematic literature review. $J$ Pain Symptom Manage. 2011;41(6):1073-1093.

66. Chien CW, Bagraith KS, Khan A, Deen M, Strong J. Comparative responsiveness of verbal and numerical rating scales to measure pain intensity in patients with chronic pain. J Pain. 2013;14(12):1653-1662.

67. Lichtner V, Dowding D, Closs SJ. The relative meaning of absolute numbers: the case of pain intensity scores as decision support systems for pain management of patients with dementia. BMC Med Inform Decis Mak. 2015;15(1):111.

68. Royall DR, Salazar R, Palmer RF. Latent variables may be useful in pain's assessment. Health Qual Life Outcomes. 2014;12:13.

69. Lichtner V, Dowding D, Esterhuizen P, et al. Pain assessment for people with dementia: a systematic review of systematic reviews of pain assessment tools. BMC Geriatr. 2014;14:138.
70. von Baeyer CL, Spagrud LJ. Systematic review of observational (behavioral) measures of pain for children and adolescents aged 3 to 18 years. Pain. 2007;127(1-2):140-150.

71. Stites M. Observational pain scales in critically ill adults. Crit Care Nurse. 2013;33(3):68-78.

72. Thimineur MA, Kravitz E, Vodapally MS. Intrathecal opioid treatment for chronic non-malignant pain: a 3-year prospective study. Pain. 2004;109(3):242-249.

73. Stearns L, Boortz-Marx R, Du Pen S, et al. Intrathecal drug delivery for the management of cancer pain: a multidisciplinary consensus of best clinical practices. J Support Oncol. 2005;3(6):399-408.

74. Webster LR. The relationship between the mechanisms of action and safety profiles of intrathecal morphine and ziconotide: a review of the literature. Pain Med. 2015;16(7):1265-1277.

75. Winkelmüller M, Winkelmüller W. Long-term effects of continuous intrathecal opioid treatment in chronic pain of nonmalignant etiology. J Neurosurg. 1996;85(3):458-467.

76. Abs R, Verhelst J, Maeyaert J, et al. Endocrine consequences of longterm intrathecal administration of opioids. J Clin Endocrinol Metab. 2000;85(6):2215-2222.

77. Kratzsch T, Stienen MN, Reck T, Hildebrandt G, Hoederath P. Cathetertip granulomas associated with intrathecal drug delivery - a two-center experience identifying 13 cases. Pain Physician. 2015;18(5):E831-E840.

78. Veizi IE, Hayek SM, Hanes M, Galica R, Katta S, Yaksh T. Primary hydromorphone-related intrathecal catheter tip granulomas: is there a role for dose and concentration? Neuromodulation. 2016;19(7):760-769.

79. Yaksh TL, Hassenbusch S, Burchiel K, Hildebrand KR, Page LM, Coffey RJ. Inflammatory masses associated with intrathecal drug infusion: a review of preclinical evidence and human data. Pain Med. 2002;3(4):300-312.

80. Thompson JC, Dunbar E, Laye RR. Treatment challenges and complications with ziconotide monotherapy in established pump patients. Pain Physician. 2006;9(2):147-152.

81. Hapidou EG, Horst E. Learning to manage chronic pain: the patients' perspective. Pain Ther. 2016;5(1):93-105.

82. Scascighini L, Toma V, Dober-Spielmann S, Sprott H. Multidisciplinary treatment for chronic pain: a systematic review of interventions and outcomes. Rheumatology (Oxford). 2008;47(5):670-678.

83. Pergolizzi J, Ahlbeck K, Aldington D, et al. The development of chronic pain: physiological CHANGE necessitates a multidisciplinary approach to treatment. Curr Med Res Opin. 2013;29(9):1127-1135.

84. Thampi SP, Rekhala V, Vontobel T, Nukula V. Patient safety in interventional pain procedures. Phys Med Rehabil Clin NAm. 2012;23(2):423-432.

\section{Journal of Pain Research}

\section{Publish your work in this journal}

The Journal of Pain Research is an international, peer reviewed, open access, online journal that welcomes laboratory and clinical findings in the fields of pain research and the prevention and management of pain. Original research, reviews, symposium reports, hypothesis formation and commentaries are all considered for publication.

\section{Dovepress}

The manuscript management system is completely online and includes a very quick and fair peer-review system, which is all easy to use. Visit http://www.dovepress.com/testimonials.php to read real quotes from published authors. 